Case report

\title{
Paradoxical myopic shift following cycloplegia in retinopathy of prematurity patients: a case series Nikolas JS London ${ }^{1,2 *}$, Susan M Carden ${ }^{3}$ and William V Good ${ }^{1,2}$
}

\author{
Addresses: ${ }^{1}$ Department of Ophthalmology, California Pacific Medical Center, 2340 Clay St. 5th Floor, San Francisco, CA 94115, USA \\ ${ }^{2}$ Smith Kettlewell Eye Research Institute, 2318 Fillmore St, San Francisco, CA 94115, USA \\ ${ }^{3}$ Department of Ophthalmology, Royal Children's Hospital, Melbourne, Victoria, 3052, Australia \\ Email: NJSL* - nik.london@gmail.com; SMC - smcarden@aol.com; WVG - good@ski.org \\ * Corresponding author
}

Received: 6 January 2009 Accepted: II August 2009 Published: 25 August 2009

Cases Journal 2009, 2:8970 doi: 10.4076/1757-1626-2-8970

This article is available from: http://jmedicalcasereports.com/jmedicalcasereports/article/view/8970

(C) 2009 London et al.; licensee Cases Network Ltd.

This is an Open Access article distributed under the terms of the Creative Commons Attribution License (http://creativecommons.org/licenses/by/3.0), which permits unrestricted use, distribution, and reproduction in any medium, provided the original work is properly cited.

\begin{abstract}
Introduction: Spectacle non-compliance is a significant problem in pediatric patients, and may have a variety of consequences. Non-compliance with myopic refractive correction could be secondary to a variety of issues, including age, discomfort, gender, urban vs. rural residence, presenting visual acuity, and degree of refractive error. We observed a phenomenon in our pediatric patients with retinopathy of prematurity that may add another possible explanation: incorrect prescription due to measures of increased, rather than decreased, myopia after cycloplegia.

Case presentation: An unmasked, prospective study of 8 consecutive patients seen in a single practice. Retinoscopic refraction measurements were obtained before and after pharmacologic cycloplegia.

In all 13 eyes, there was either no change ( 2 eyes) or a myopic shift (II eyes) in the measured refractive error. The average change in refraction was -1.58 and -1.54 for the right and left eyes, respectively (range 0 to -3.00 OD and 0 to -3.00 OS).

Conclusions: The contribution of ocular components to refractive status differs between ROP and non-ROP eyes. Unanticipated myopic shift following cycloplegia in ROP patients may result in inappropriate glasses prescription with poor correction of visual acuity. This may contribute to spectacle noncompliance in this group.
\end{abstract}

\section{Introduction}

Spectacle non-compliance is occasionally encountered in pediatric patients $[1,2]$, even though refractive errors may have significant functional, economic, medical, and educational consequences. Non-compliance with myopic refractive correction could be secondary to a variety of issues, including age, discomfort, gender, urban vs. rural residence, presenting visual acuity, and degree of refractive error [2,3]. In pediatric patients with retinopathy of prematurity (ROP), we found increased rather than 
decreased myopia after cycloplegia. This finding may be of interest to ophthalmologists who care for children with resolved, advanced ROP.

\section{Case presentation Methods}

Ethics committee approval was obtained from the Smith Kettlewell Eye Research Institute. We collected our data in a prospective, but unmasked fashion. The cases were accumulated from 8 consecutive ROP patients seen by one author (WVG) in his office, with no others left out (Table 1). Informed consent for participation was obtained for each patient from the patients' parents. None of these children participated in the Early Treatment for Retinopathy of Prematurity Study. The patients ranged in age from 8 months to 7 years, with an average age of 41 months. For each patient, manifest and cycloplegic refractions were measured in both eyes, and the difference between the two measurements was determined. Cycloplegia was accomplished with tropicamide $1 \%$. Measurements were obtained using a retinoscope (Welch Allyn, Skaneateles Falls, NY, USA) from 13 of 16 eyes, limited in 3 eyes by stage 5 disease.

\section{Results}

In all 13 eyes, there was either no change ( 2 eyes) or a myopic shift (11 eyes) in the measured refractive error. The average change in refraction was -1.58 and -1.54 for the right and left eyes, respectively (range 0 to $-3.00 \mathrm{OD}$ and 0 to -3.00 OS).

\section{Discussion}

Cycloplegic refraction should provide the most hyperopic refraction possible for an individual, because cycloplegic agents paralyze muscles involved in accommodation. Studies on the effect of cycloplegia have not evaluated children who recovered from advanced ROP, however.

The shift toward myopia after cycloplegia in children who had advanced ROP can be explained by a difference in the contribution of ocular components to refractive status differs between ROP and non-ROP eyes. In patients

Table I. Summary of data for all patients indicating age and manifest (MRx) and cycloplegic (CRx) refractive error measurements in right and left eyes

\begin{tabular}{llllll}
\hline Patient \# & Age & MRx OD & MRx OS & CRx OD & CRx OS \\
\hline I & 4 years & -5.25 & -4.00 & -6.25 & -4.50 \\
2 & 8 months & 1.50 & 1.25 & -1.50 & -1.75 \\
3 & 6 years & -8.75 & stage 5 & -9.50 & stage 5 \\
4 & 16 months & -1.75 & -1.75 & -4.00 & -4.00 \\
5 & 7 years & stage 5 & -7.50 & stage 5 & -7.50 \\
6 & 3 years & stage 5 & -19.00 & stage 5 & -22.00 \\
7 & 3 years & -7.50 & -4.50 & -8.00 & -5.00 \\
8 & 2 years & -8.50 & -7.50 & -10.50 & -9.00 \\
\hline
\end{tabular}

$M R x$, manifest refraction; $C R x$, cycloplegic refraction; $O D$, right eye; $O D$, left eye. without ROP, the refractive state of the eye is most strongly correlated with the axial length of the eye, less so with corneal curvature or anterior chamber depth, and not correlated with the power of the lens $[4,5]$. In children with a history of advanced ROP, axial length does not change much, and myopia is primarily lenticular in etiology [6,7]. The lens edge is more refractive than its center, and the lens may be more spherical and anteriorized, due to peripheral ROP retinal cicatricial changes. Lenticular myopia is noted even in normal adult eyes in dim lighting and after cycloplegia [8-10].

Following recovery from ROP, it is likely that the affected eye has a new constellation of factors that contribute to refractive status. This study looks at cases of myopia after cycloplegia, and is not controlled. Nevertheless, attention should be given to the manifest refraction in infants who had advanced ROP. In some instances, paradoxical myopia could explain spectacle non-compliance. This study has several limitations. Scientific rigor is limited in uncontrolled case series. Also we have a relatively small cohort of eight patients. Moreover, we have no evidence to support our assertion that an incorrect spectacle prescription is associated with non-compliance. However, this phenomenon has not been reported previously, and should be considered when measuring glasses ROP patients.

\section{Consent}

Written informed consent was obtained from all patients for publication of this case series. A copy of the written consent is available for review by the Editor-in-Chief of this journal.

\section{Competing interests}

The authors declare that they have no competing interests.

\section{Authors' contributions}

NL analyzed and interpreted patient data and was a major contributor in writing the manuscript. SC helped to interpret data and assisted in writing. WG examined all of the patients, collected data, and contributed to the writing of the manuscript. All authors read and approved the final manuscript.

\section{Acknowledgement}

The authors would like to thank the Pacific Vision Foundation for assistance in funding this study. Dr. Good is supported by a grant from the National Institutes of Health, National Eye Institute EY015228.

\section{References}

I. Preslan MW, Novak A: Baltimore Vision Screening Project. Phase 2. Ophthalmology 1998, 105:150-153.

2. Horwood AM: Compliance with first time spectacle wear in children under eight years of age. Eye 1998, I2:173-178. 
3. Castanon Holguin AM, Congdon N, Patel N, Ratcliffe A, Esteso P, Toledo Flores S, Gilbert D, Pereyra Rito MA, Munoz B: Factors associated with spectacle-wear compliance in school-aged Mexican children. Invest Ophthalmol Vis Sci 2006, 47:925-928.

4. Zadnik K, Mutti DO, Mitchell GL, Jones LA, Burr D, Moeschberger M: Normal eye growth in emmetropic schoolchildren. Optom Vis Sci 2004, $81: 819-828$.

5. Zadnik K, Mutti DO, Friedman NE, Adams AJ: Initial crosssectional results from the Orinda Longitudinal Study of Myopia. Optom Vis Sci 1993, 70:750-758.

6. Garcia-Valenzuela E, Kaufman LM: High myopia associated with retinopathy of prematurity is primarily lenticular. J Aapos 2005, 9:121-128.

7. Gordon RA, Donzis PB: Myopia associated with retinopathy of prematurity. Ophthalmology 1986, 93:1593-1598.

8. Wang Y, Zhao K, Jin Y, Niu Y, Zuo T: Changes of higher order aberration with various pupil sizes in the myopic eye. J Refract Surg 2003, 19:S270-S274.

9. Toh T, Kearns LS, Scotter LW, Mackey DA: Post-cycloplegia myopic shift in an older population. Ophthalmic Epidemiol 2005, I 2:215-219.

10. Carkeet A, Velaedan S, Tan YK, Lee DY, Tan DT: Higher order ocular aberrations after cycloplegic and non-cycloplegic pupil dilation. J Refract Surg 2003, 19:316-322.

\section{Do you have a case to share?}

Submit your case report today

- Rapid peer review

- Fast publication

- PubMed indexing

- Inclusion in Cases Database

Any patient, any case, can teach us something

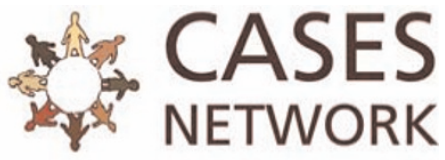

www.casesnetwork.com 